\title{
EFEKTIVITAS VENTILASI RUMAH LINGKUNGAN PADAT DI PERUMNAS DEPOK TIMUR
}

\author{
Dian Nugraha \\ Universitas Indraprasta PGRI, Program Studi Arsitektur \\ nurgaha_28@yahoo.com
}

\begin{abstract}
:
In tropical climates moist, in general building is designed with vaporization system natural maximize velocity of the wind to be able to cool the structure of the building or the achievement of physiological comfort. The concept of design with vaporization system natural maximize velocity of the wind, in addition to monitoring the development of the rush of winds, also identify the effects the environment and local buildings to the flow of the wind.Comfort thermal influenced by the physical environment, among others the temperature of the air, the relative humidity, velocity of the wind, and being affected by non-physical environment, including types of sex, the age of, garment used and types of activity is doing. To the increase of the buildings and the form of dwelling that only have one fasade, needs to be stratagem to be able to use the climate condition and the form of the roof on the building of a dwelling house. This research to know and then to analyze natural penghawaan performance with a vent the roof of a building a simple house on the environment to the density of the high.In the planning of the design needed to do the housing that berkepadatan high in mensiasati were naturally ventilated thermal within a building for convenience .The research also to analyze the current positions of the ventilation elements of a roof which are optimal and have become important in creating and affect the inhabitants of the physiological comfort.
\end{abstract}

Key Words: Air, Building Density, ventilation

\begin{abstract}
Abstrak :
Di iklim tropis lembab, pada umumnya bangunan-bangunan didesain dengan sistem penghawaan alami yang memaksimalkan kecepatan angin untuk dapat mendinginkan struktur bangunan ataupun pencapaian kenyamanan fisiologis. Konsep desain dengan sistem penghawaan alami yang memaksimalkan kecepatan angin, selain memperhatikan pergerakan aliran angin, juga melihat pengaruh lingkungan dan bangunan sekitar terhadap aliran angin tersebut. Kenyamanan termal dipengaruhi oleh lingkungan fisik, antara lain temperatur udara, kelembaban relatif, kecepatan angin, dan dipengaruhi oleh lingkungan non fisik, antara lain jenis kelamin, umur, pakaian yang digunakan dan jenis aktifitas yang sedang dikerjakan. Dengan padatnya bangunan dan bentuk hunian yang hanya mempunyai satu fasade, maka perlu siasat untuk dapat memanfaatkan kondisi iklim dan bentuk atap pada bangunan rumah tinggal. Penelitian ini untuk mengetahui dan menganalisa kinerja penghawaan alami dengan ventilasi atap bangunan rumah sederhana pada lingkungan dengan kepadatan tinggi. Perlu strategi dalam perencanaan desain perumahan yang berkepadatan tinggi dalam mensiasati ventilasi alami untuk kenyamanan thermal dalam bangunan. Penelitian ini juga untuk menganalisa letak elemen ventilasi atap yang optimal dan mempunyai kontribusi dalam menciptakan dan mempengaruhi kenyamanan fisiologis penghuni.
\end{abstract}

Kata Kunci : Udara, Kepadatan Bangunan, Ventilasi

\section{PENDAHULUAN}

Memiliki posisi geografis yang terletak di sepanjang garis khatulistiwa, menyebabkan Indonesia memiliki jenis iklim panas dan lembab. Iklim tropis lembab menurut Egan (1999) \& Szokolay (2004), memiliki karakteristik curah hujan dan kelembaban relatif tinggi, temperatur udara moderat dengan variasi perbedaan temperatur yang kecil sepanjang hari maupun sepanjang musim, kecepatan angin rendah, serta intensitas cahaya matahari yang cukup tinggi. Kondisi tersebut membutuhkan desain pada bangunan yang tanggap terhadap iklim.

Kenyamanan bangunan erat hubungannya dengan kondisi alam atau lingkungan disekitar dan upaya pengkondisian ruang dalam bangunan. Menurut Aynsley (1977)\& Awbi (2003), kenyamanan dalam pengkondisian ruangan dipengaruhi oleh lingkungan fisik, diantaranya suhu/temperatur udara, kelembaban relatif, kecepatan angin. Ketiganya mempunyai hubungan yang saling berkaitan untuk mencapai kenyamanan termal bagi penghuni. Hal ini dapat dikatakan bahwa kenyamanan fisiologis akan 
dapat tercapai jika nilai kecepatan angin berada pada kondisi seimbang antara temperatur dan kelembaban relatif tertentu.

Bangunan rumah yang mempunyai orientasi utara, selatan, timur dan barat memiliki desain yang sama, hal ini tidak sesuai dengan prinsip pendinginan pasif yang akan berbeda dalam setiap orientasi. Karena keterbatasan lahan, maka sekarang muncul pembangunan perumahan yang dibangun dengan model deret, sehingga hanya mempunyai 2 fasade depan dan belakang. Kepadatan bangunan adalah merupakan satu dari faktor-faktor prinsip yang mempengaruhi kondisi iklim mikro dan menentukan kondisi ventilasi maupun kondisi suhu udara. Gejala pemanasan kota utamanya agak dipengaruhi oleh kepadatan kota daripada ukuran dari kota itu sendiri, semakin padat bangunan semakin buruk kondisi ventilasi.(Santosa : 2000, Santoso : 2007, Sukawi : 2013)

Menurut Subagyo dalam Budiani (2009) efektifitas adalah kesesuaian antara output dengan tujuan yang ditetapkan. Efektifitas adalah suatu keadaan yang terjadi karena dikehendaki. Menurut Richard Steer, efektifitas harus dinilai atas dasar tujuan yang bisa dilaksanakan, bukan atas dasar konsep tujuan yang maksimum. Efektifitas diukur dengan menggunakan standar sesuai dengan acuan Litbang Depdagri dalam Budiani (2009) seperti pada tabel dibawah.

Tabel 1. Rasio Efektivitas

\begin{tabular}{|c|c|}
\hline Rasio Efektifitas & Tingkat Capaian \\
\hline Dibawah 40 & Sangat Tidak Efektif \\
$40-59,99$ & Tidak Efektif \\
$60-79,99$ & Cukup Efektif \\
Di atas 80 & Sangat Efektif \\
\hline
\end{tabular}

Sumber : Litbang Depdagri, 1991 dalam Budiani 2009

Ventilasi alamiah adalah pertukaran udara di dalam suatu bangunan dengan udara di luarnya tanpa menggunakan kipas atau peralatan mekanik lainnya (Croome, 2003), juga sering disebut sebagai pengendalian atau kontrol pasif, dengan kata lain tanpa adanya perlakuan mekanis. Ventilasi alamiah terjadi akibat adanya dua factor pemicu mekanisme pergerakan fluida.

Faktor yang mempengaruhi laju ventilasi yang disebabkan gaya angin termasuk adalah : kecepatan rata-rata, arah angin yang kuat, variasi kecepatan dan arah angin musiman dan harian, dan hambatan setempat, seperti bangunan yang berdekatan, bukit, pohon dan semak belukar.

Liddamnet (1988) meninjau relevansi tekanan angin sebagai mekanisme penggerak.
Model simulasi lintasan aliran jamak dikembangkan dan menggunakan ilustrasi pengaruh angin pada laju pertukaran udara. Kecepatan angin biasanya terendah pada musim panas dari pada musim dingin. Pada beberapa tempat relatif kecepatannya di bawah setengah rata-rata untuk lebih dari beberapa jam per bulan. Karena itu, sistem ventilasi alami sering dirancang untuk kecepatan angin setengah rata-rata dari musiman.

Pengertian dasar permukiman dalam Undang-Undang No.1 tahun 2011 adalah bagian dari lingkungan hunian yang terdiri atas lebih dari satu satuan perumahan yang mempunyai prasarana, sarana, utilitas umum, serta mempunyai penunjang kegiatan fungsi lain dikawasan perkotaan atau kawasan perdesaan. Menurut Koestoer (1995) batasan permukiman adalah terkait erat dengan konsep lingkungan hidup dan penat aan ruang. Permukiman adalah area tanah yang digunakan sebagai lingkungan tempat tinggal atau lingkungan hunian dan tempat kegiatan yang mendukung peri kehidupan dan merupakan bagian dari lingkungan hidup di luar kawasaan lindung baik yang berupa kawasan perkotaan maupun perdesaan.

Parwata (2004) menyatakan bahwa permukiman adalah suatu tempat bermukim manusia yang telah disiapkan secara matang dan menunjukkan suatu tujuan yang jelas, sehingga memberikan kenyamanan kepada penghuninya.Permukiman ( Settlement ) merupakan suatu proses seseorang mencapai dan menetap pada suatu daerah ( Van der Zee 1986 ).Kegunaan dari sebuah permukiman adalah tidak hanya untuk menyediakan tempat tinggal dan melindungi tempat bekerja tetapi juga menyediakan fasilitas untuk pelayanan, komunikasi, pendidikan dan rekreasi.

\section{METODOLOGI}

Metode Penelitian yang digunakan dalam penelitian ini adalah Metode Observasi dengan survey deskriptif. Obyek penelitian adalah bangunan rumah tinggal yang mempunyai kepadatan tinggi pada hunian yang tertata pada perumahan sederhana yang dikembangkan oleh perum Perumnas. survey diskriptif bertujuan untuk mencari fenomena/ gejala dengan jalan observasi. Metode Observasi yaitu metode yang dilakukan dengan pengamatan langsung, pengukuran dan pencatatan terhadap gejala atau fenomena yang diteliti. (Arikunto, 1998).

Metode dalam penelitian ini berupa pengamatan, pencatatan dari pengukuran titik titik 
didalam dan diluar rumah dengan alat bantu seperti thermometer (untuk mengukur suhu luar ruang maupun dalam ruang), hygrometer (untuk mengukur kelembaban), hot wire anemometer (untuk mengukur pergerakan udara baik didalam ruangan maupun diluar ruangan).

Penentuan titik pengukuran yang berada di dalam rumah dilakukan pada ruang tamu atau ruang keluarga dan ruang makan atau dapur yang berada di bagian belakang dalam tata ruang rumah. Sedangkan pengukuran pada luar ruangan dilakukan pada teras dan pada jalan di depan rumah tinggal. Pengumpulan data primer yang diperoleh di lapangan, akan di croschek dengan data sekunder berupa suhu, kelembaban dan pergerakan angin dari BMKG untuk melihat kondisi iklim makro perkotaan dan lingkungan.

\section{HASIL DAN PEMBAHASAN}

Perumahan Depok Timur merupakan perumnas tahap ke 3 yang direncanakan bagi keluarga kecil yang baru menikah dan membutuhkan tempat tinggal. Lokasi Berada di Depok TImur Jawa barat Tipe rumah yang ada dilokasi tersebut adalah tipe 21 dengan luas tanah $90 \mathrm{~m}^{2}$.

Dengan Berkembangannya kebutuhan akan ruang penghuni diperumnas tersebut akhirnya mengembang bangunannya sehingga tanah yang tersisa telah terbangun sehingga mengakibatkan hanya menyediakan bukaan pada satu sisi (di fasade depan) maka penelitian ini mencoba untuk mengetahui efektivtas udara yang masuk sesuaikah dengan standar nasional Indonesia dan kesehatan

Pergerakan angin atau pergerakan udara di dalam ruangan, dapat terjadi akibat perbedaan suhu. Pergerakan angin terjadi karena perbedaan tekanan antara dua sisi fasade bangunan, yang secara alami angin akan bergerak dari tekanan yang tinggi (+) ke tekanan yang rendah (-).

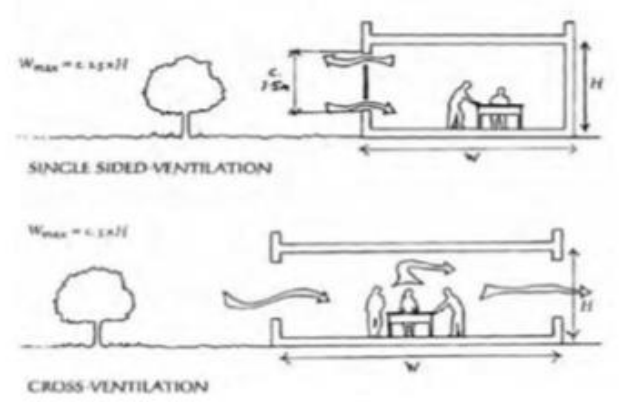

Gambar 1. Arah Angin pada Ventilasi single sided-ventilation (Gambar 1 atas) adalah ventilasi dengan hanya memanfaatkan bukaan pada salah satu sisi ruangan. Lain halnya dengan cross-ventilation (Gambar 2. bawah) yang memanfaatkan bukaan pada dua atau lebih sisi ruangan. Single sided-ventilation tidak efektif untuk diterapkan di daerah beriklim panas sehingga diperlukan banyak bukaan untuk mendukung cross-ventilation. Single sidedventilation juga hanya cocok untuk ruanganruangan kecil.
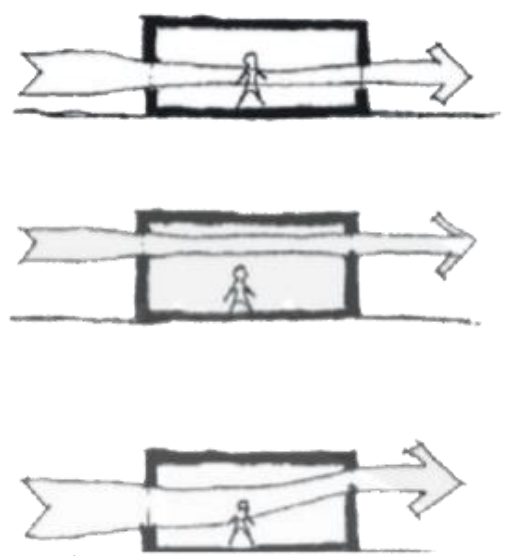

Gambar 2. Posisi inlet dan outlet berpengaruh terhadap arah angin di dalam ruangan/bangunan (Sumber: Mediastika)

Pemanfaatan comfort ventilation pada bangunanbangunan di daerah beriklim panas lembab perlu mengikuti panduan-panduan berikut. (Lechner, 2000, hal. 269)

- pergerakan udara pada penghuni maksimal

- insulasi seperlunya

- luas lubang jendela/ventilasi $20 \%$ dari luas lantai dengan ukuran inlet dan outlet yang hampir sama

- jendela terbuka sepanjang hari
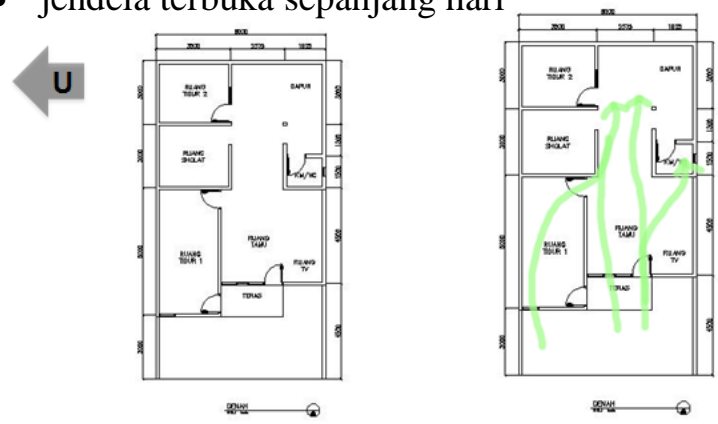

Gambar 3. Denah Rumah dan Arah Aingin dalam Rumah 

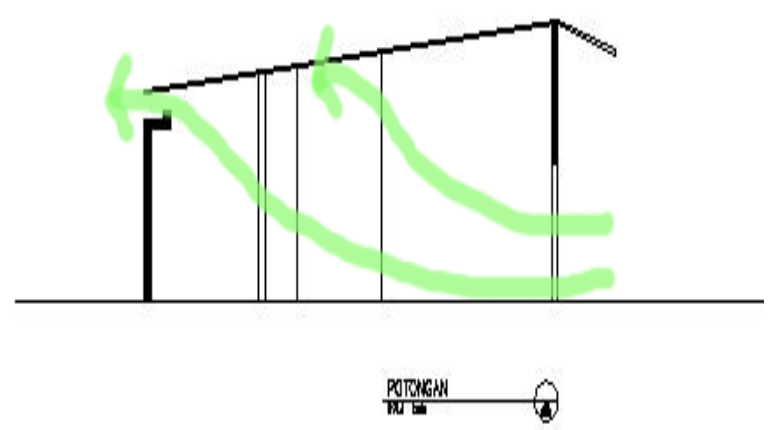

Gambar 4. Arah Angin dalam Potongan Rumah

Pada sample rumah yang diambil menggunakan sistem ventilasi rumah cross ventilasi yaitu : yang memanfaatkan bukaan pada dua atau lebih sisi ruangan

\section{Ruang Tamu}

Luas Bidang : $92,4 \mathrm{~m}^{2}$

Luas Bukaan/Ventilasi : 4,535 $\mathrm{m}^{2}$

$92,4 \mathrm{~m}^{2}-4.535 \mathrm{~m}^{2}=87,865 \mathrm{~m}^{2}$

$=0,5 \times 87,865 \mathrm{~m}^{2} \times 0,3 \mathrm{~m} / \mathrm{s}$

$=0,15 \mathrm{~m}^{3} / \mathrm{s}$

Tabel 2. Perhitungan Persentasi Bukaan terhadap Luas Bidang

\begin{tabular}{|c|c|c|c|c|c|c|}
\hline $\begin{array}{l}\mathrm{N} \\
\mathrm{o}\end{array}$ & $\begin{array}{l}\text { Nama } \\
\text { Ruang }\end{array}$ & $\begin{array}{c}\text { Luas } \\
\text { Buka } \\
\text { an }\end{array}$ & $\begin{array}{l}\text { Luas } \\
\text { Bidang }\end{array}$ & $\begin{array}{c}\text { Kecepa } \\
\text { tan } \\
\text { Angin }\end{array}$ & $\begin{array}{c}\text { Persentas } \\
\text { e Luas } \\
\text { Bukaan } \\
\text { terhadap } \\
\text { Luas } \\
\text { bidang }\end{array}$ & $\begin{array}{c}\text { Efekti } \\
\text { vitas }\end{array}$ \\
\hline 1 & $\begin{array}{c}\text { Ruang } \\
\text { Tamu } \\
\& \\
\text { dapur }\end{array}$ & $\begin{array}{c}4,53 \\
5 \mathrm{~m} 2\end{array}$ & $\begin{array}{c}92,4 \\
\mathrm{~m} 2\end{array}$ & $0.3 \mathrm{~m} / \mathrm{s}$ & $4,9 \%$ & $\begin{array}{l}\text { Sangat } \\
\text { efektiv }\end{array}$ \\
\hline 2 & $\begin{array}{c}\text { Ruang } \\
\text { tidur } \\
\text { Depan }\end{array}$ & $\begin{array}{c}4,49 \\
5 \mathrm{~m} 2\end{array}$ & $\begin{array}{c}52,2 \\
\mathrm{~m} 2\end{array}$ & $0 \mathrm{~m} / \mathrm{s}$ & $8,61 \%$ & $\begin{array}{c}\text { Tidak } \\
\text { efektiv }\end{array}$ \\
\hline 3 & $\begin{array}{l}\text { Ruang } \\
\text { Shalat }\end{array}$ & $\begin{array}{l}2.73 \\
5 \mathrm{~m} 2 \\
\end{array}$ & $\begin{array}{c}36,75 \\
\mathrm{~m} 2\end{array}$ & $0 \mathrm{~m} / \mathrm{s}$ & $7,4 \%$ & $\begin{array}{c}\text { Tidak } \\
\text { efektiv }\end{array}$ \\
\hline 4 & $\begin{array}{c}\text { Ruang } \\
\text { Tidur } \\
\text { Belak } \\
\text { ang } \\
\end{array}$ & $\begin{array}{l}3.63 \\
\mathrm{~m} 2\end{array}$ & $\begin{array}{c}36,6 \\
\mathrm{~m} 2\end{array}$ & $0 \mathrm{~m} / \mathrm{s}$ & $9,91 \%$ & $\begin{array}{c}\text { Tidak } \\
\text { efektiv }\end{array}$ \\
\hline
\end{tabular}

Pada tabel persentase luas bukaan terhadap luas dinding menunjukkan bahwa persentase bukaan belum sesuai dengan standar bukaan yaitu minimal $20 \%$ dari luas bidang dinding tetapi pada ruang tamu dan Dapur justru persentase luas bukaan kurang dari $20 \%$ tetapi kecepatan angin di dalam ruang tersebut mencapai $0,3 \mathrm{~m} / \mathrm{s}$.

\section{PENUTUP}

\section{Simpulan}

Pada kasus ini dapat disimpulkan bahwa :

1. Faktor arah mata angin menjadi faktor utama dalam mengaliri udara kedalam ruang, dilihat pada ruang tamu bukaan yang kurang dari standar yaitu $20 \%$ tetapi kecepatan angin mencapai $0,3 \mathrm{~m} / \mathrm{s}$

2. Inlet pada ruang tamu menghadap ke ruang terbuka sehingga pergerakan udara ke dalam cukup banyak dan karena letak ruang tamu berada bagian depan rumah.

3. Pada ruang tidur depan inlet kurang dari $20 \%$ dan tidak ada pergerakan udara didalamnya hal ini disimpulkan bahwa:

- bukaan yang terlalu kecil

- letak bukaannya berada di sudut bangunan walaupun menghadap ruang terbuka ( dapat dilihat diphoto 4 lampiran)

- dari sisi utara terhalang oleh dinding.

\section{Saran}

Agar udara dapat mengaliri semua ruang maka dibutuhkan inlet dan oulet yang cukup, dan peletakan inlet juga harus diperhatikan. Pada ruang tidur depan sebagai inlet yang utama diperlukan bukaan yang besar sebagai salah satu jalan untuk mengaliri udara ke ruang sholat dan kamar tidur dibelakang.

Ruang sholat dan ruang tidur belakang mempunyai inlet tetapi tidak ada mempunyai tidak oulet sehingga aliran udara tidak berjalan dengan baik sehingga pada ruang tersebut dibutuhkan oulet pada bagian atas agar privasi tetap terjaga.

\section{DAFTAR PUSTAKA}

Allard Francis \& Ghiaus Cristian. (2005) Natural Ventilation in the Urban Environment, assessment and design. Earthscan, London

Arikunto, Suharsimi, (1998), Prosedur Penelitian Suatu Pendekatan Praktek, Rineka Cipta, Jakarta.

Aynsley, R.M. (1977) Architectural Aerodynamics. Applied Science publishers LTD, London

Croome, Derek Clements, (2003), Naturally Ventilated Buildings : Buildings for thr senses, the economy and society, E\&FN Spon, London.

Egan,David (1999), Concepts In Thermal Comfort (Terjemahan), Malang, UNMER Press.

Febrrita Awbi, Hazim B.(2003), Ventilation of Building, Spon Press, London.

Febrita Yuswinda. (2011) Ventilasi Solar Chimney sebagai Alternatif Desain Pasive Cooling 
di Iklim Tropis Lembab, Jurnal Ruang Vol 2 No 12011.

Pranoto, Mohammad S (2007), Kajian Ventilasi Atap Rumah Berbasis Rumah Joglo Mangkurat, Jurnal Rekayasa Perencanaan vol. 3, no. 3, juli 2007.

Purwanto, LMF, (2006), Pengaruh bentuk atap bangunan tradisional di jawa tengah untuk peningkatan kenyamanan termal bangunan.

Jurnal Dimensi Arsitektur vol. 34, no. 2, desember 2006, 154 - 160. Roulet, Claude Alain,(2008), Ventilation and Airflow in Buildings, Methods for Diagnosis and evaluation, Earthscan, London.

Samodra, FX. T.B.S. (2005) Thermal Performance Optimization for Javanese Village Houses.

Proceeding International Seminar SENVAR VI ITB Bandung. September 19-20. pp 19-25 Santosa, M. (2000) Specific Responses of Traditional Houses to Hot Tropic, Proceedings

SENVAR2000 ITS Surabaya, October 23-24. pp 13-17. Santoso Heru B, Santosa, M. (2007) Kajian Termal Bangunan pada Lingkungan Berkepadatan Tinggi dengan Variabel Atap, Dinding, Ventilasi dan Plafon, Jurnal Gema Teknik No1 tahun X Januari 2007.

Santamouris, Mat (1997), Passive Cooling of Building, James and James, London

Sukawi (2010), Kaitan Desain Selubung Bangunan terhadap Pemakaian Energi dalam Bangunan, Proseding Seminar energi UNWAHAS Semarang.

Sukawi, Dwiyanto Agung (2013), Potensi Ventilasi Atap Terhadap Pendinginan Pasif Ruangan pada Pengembangan Rumah Sederhana, Proseding Seminar IPLBI Universitas Hasanuddin Makasar.

Szokolay, S.V. (2004) Introduction to Architectural Science : The Basis of Sustainable Design. Architectural Press, Singapore
Prosiding SNST ke-6 Tahun 2015. Fakultas Teknik Universitas Wahid Hasyim Semarang 31 